\title{
Association of Argonaute proteins and microRNAs can occur after cell lysis
}

\author{
KASANDRA J. RILEY, ${ }^{1}$ THERESE A. YARIO, and JOAN A. STEITZ ${ }^{2}$ \\ Department of Molecular Biophysics and Biochemistry and the Howard Hughes Medical Institute, Yale University School of Medicine, \\ New Haven, Connecticut 06536, USA
}

\begin{abstract}
MicroRNA (miRNA) target identification is a challenging but important endeavor. Global analyses of the direct mRNA targets of miRNAs have relied heavily upon immunopurification techniques, wherein a core protein component of the miRNA-protein complex, Argonaute (Ago), is immunoprecipitated to isolate associated RNAs. This approach involves the assumption that the selected RNAs were bound to the Ago protein in vivo and that the methodology did not significantly perturb endogenous interactions or produce novel interaction artifacts. To test whether RNAs that coimmunoprecipitate with human Ago were bound in vivo or could associate post-cell lysis, we used an experimental approach that distinguishes between these two origins of interaction. We show that a transfected miRNA mimic, but not a plasmid-expressed miRNA, can interact with human Ago proteins post-lysis. Our results have important implications for the design of miRNP immunoprecipitation experiments.
\end{abstract}

Keywords: microRNA; RIP; Argonaute

\section{INTRODUCTION}

The biological function of a microRNA (miRNA) is defined by the mRNAs that it targets. From the moment that miRNAs were discovered, the identities of the mRNAs they bind in vivo have been pursued (for a recent review, see Pasquinelli 2012). Unfortunately, miRNA target identification has proven to be challenging, due in part to the imperfect and variable nature of miRNA-mRNA base-pairing (Lewis et al. 2005; Didiano and Hobert 2006; Grimson et al. 2007; Shin et al. 2010; Chi et al. 2012). The limitations of bioinformatic miRNA target prediction necessitate the use of biochemical approaches. Immunopurification of ribonucleoprotein (RNP) complexes from cell lysates has been used extensively to study miRNAs and their mRNA targets (Rio et al. 2011).

MiRNA-mediated regulation is thought to require minimally the stable interaction of a mRNA with a miRNA and an Argonaute (Ago) protein, comprising a tightly associated miRNA-associated RNP (miRNP), which is the core of the RNA-induced silencing complex (RISC) (Pillai 2005;

\footnotetext{
${ }^{1}$ Present address: Department of Chemistry, Rollins College, Winter Park, FL 32789, USA

${ }^{2}$ Corresponding author

E-mail joan.steitz@yale.edu

Article published online ahead of print. Article and publication date are at http://www.rnajournal.org/cgi/doi/10.1261/rna.034934.112.
}

Wang et al. 2008). Human cells possess four Ago proteins (Ago1-4), all $\sim 100 \mathrm{kDa}$ and ubiquitously expressed (for review, see Ender and Meister 2010). The four human Ago proteins have overlapping biological functions and are roughly equivalent in their affinity for bulged miRNA-type duplexes with mRNA (Su et al. 2009). Since an Ago protein must bind a single-stranded mature miRNA before this binary complex engages in mRNA target recognition, the miRNA-Ago interaction is a crucial step in determining the specificity of miRNA targeting (Czech and Hannon 2011).

The high affinity of association between Ago and RNAs $\left(\mathrm{K}_{\mathrm{d}}=10-80 \mathrm{nM}\right.$ for tagged mammalian Ago2 binding to mature miRNAs) (Lima et al. 2009; Tan et al. 2009) is exploited in the biochemical identification of miRNAtargeted mRNAs, where the miRNP complex is precipitated with anti-Ago antibodies. The biggest assumption underlying this methodology is that the biochemical manipulations of the procedure generate selected complexes that are representative of the in vivo miRNP (Mili and Steitz 2004). In some cases, tagged Ago proteins and/or miRNAs (synthetic mature miRNA mimics, pre-miRNA mimics, or plasmid-expressed miRNAs) have been transiently or stably transfected or transduced into cells before anti-Ago immunoprecipitation (Easow et al. 2007; Karginov et al. 2007; Orom and Lund 2007; Hendrickson et al. 2008; Hong et al. 2009; Dolken et al. 2010; Hafner et al. 2010; Wang et al. 2010). Two major experimental protocols are then used: 
(1) a simple RNA coimmunoprecipitation (RIP), where mRNAs in the cell lysate are coprecipitated with Ago (Easow et al. 2007; Karginov et al. 2007; Hendrickson et al. 2008; Hong et al. 2009; Dolken et al. 2010; Wang et al. 2010), or (2) crosslinking and immunoprecipitation (CLIP), which incorporates an in vivo UV crosslinking step to covalently link Ago to miRNAs and mRNAs prior to immunoprecipitation (Chi et al. 2009; Hafner et al. 2010). The crosslinking step irreversibly locks the complexes in their in vivo state, permitting stringent purification of the RNP and identification of binding sites (Ule et al. 2005). However, it is argued by those who use RIP procedures that crosslinking is inefficient and can lead to sequence bias (Keene et al. 2006).

RIP experiments for the RNA-binding protein $\mathrm{HuR}$ demonstrated that, in the absence of crosslinking prior to preparation of the cell lysate, $\mathrm{HuR}$ artificially binds mRNAs ex-vivo (Mili and Steitz 2004). If the same holds true for Ago, then both miRNAs and their targets could be incorrectly identified in RIP-type experiments. Here, we asked whether Ago proteins can bind to miRNAs not present in vivo during a RIP procedure. We show that transfected, synthetic miRNA mimics used at manufacturer-recommended concentrations-but not plasmidexpressed miRNAs_-can interact with Ago after cell lysis. Our findings have important implications for the design of miRNP selection experiments.

\section{RESULTS AND DISCUSSION}

A diagram of the experimental approach is depicted in Figure 1A. Separate HEK293T cell populations were transfected in parallel and then lysed together pairwise prior to immunoprecipitation. For our analyses, we chose the Epstein-Barr virus (EBV) miRNA BHRF1-2 (Pfeffer et al. 2004), which is expressed in EBV-infected cells such as Raji, but not in HEK293T cells (Fig. 1B). Mature BHRF1-2 originated from the transfection of either a double-stranded synthetic miRNA mimic or a plasmid containing the BHRF1-2 pri-miRNA genomic sequence (pcDNA3-BHRF1-2). We examined two concentrations of mimic: "high" (38 nM), the quantity recommended by the transfection reagent manufacturer, or "low" (2 nM). The pcDNA3-BHRF1-2 plasmid was transfected at the maximum recommended amount. A direct comparison of the amounts of mature BHRF1-2 produced in these experimental conditions is shown in Figure 1B. To distinguish transfected Ago from endogenous Ago proteins in the coimmunoprecipitations, we used HA-tagged Ago. We tested "HI" amounts (2 $\mu \mathrm{g}$ of transfected plasmid) of either human Ago1 or Ago2, and a "LO" amount of Ago2 (100 ng of transfected plasmid). A direct comparison of the quantity of Ago proteins relative to endogenous levels is provided in Figure 1C.

To test whether Ago can bind miRNAs after cell lysis, we conducted four anti-HA coimmunoprecipitation experiments,
A
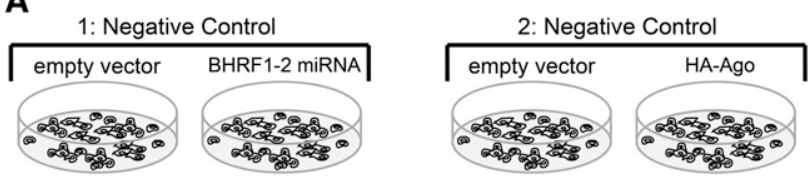

3: Positive Control

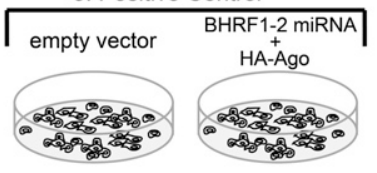

4: Experimental

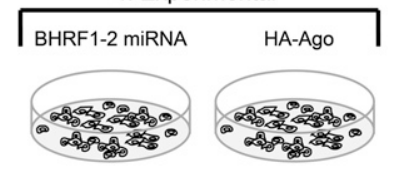

B

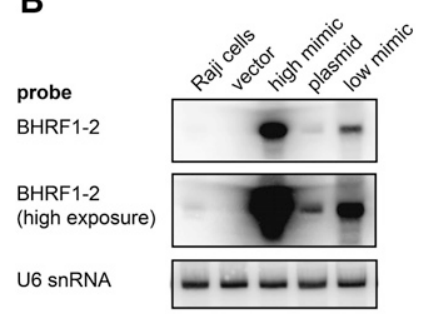

C antibody
anti-HA
anti-GAPDH
anti-Ago2

FIGURE 1. Design of coimmunoprecipitation experiments and controls. (A) Schematic diagram of the transfected HEK293T cell populations that were mixed before coimmunoprecipitation. Cells were transfected for $24 \mathrm{~h}$ with equal amounts of the noted plasmids and/or synthetic miRNAs. Each pair of separately transfected wells was harvested in PBS and mixed immediately prior to lysis and immunoprecipitation with anti-HA antibody. (B) Northern blot of $50 \mu \mathrm{g}$ of total RNA from Raji cells (first lane) or transfected HEK293T cells (remaining lanes) for miRNA BHRF1-2 relative to endogenous U6 snRNA (loading control). HEK293T cells were transfected with $2 \mu \mathrm{g}$ of empty vector (vector), $38 \mathrm{nM}$ synthetic BHRF1-2 (high mimic), $2 \mu \mathrm{g}$ of pcDNA3-BHRF1-2 (plasmid), or $2 \mathrm{nM}$ synthetic BHRF1-2 (low mimic). (C) Western blots using the indicated antibodies to determine the levels of endogenous (vector) or transfected HA-Ago proteins with a GAPDH loading control in HEK293T cells.

each exploring different HA-Ago proteins and/or miRNAs (Fig. 2). Using manufacturer-recommended quantities of HA-Ago2 plasmid and BHRF1-2 mimic in standard HEK293T transfections, immunoprecipitations of mixed cell lysates were carried out as depicted in Figure 1A. BHRF1-2 does not coprecipitate when HA-Ago2 is not present (Fig. 2A, lane 1), but does coprecipitate when the same cells were cotransfected with HA-Ago2 (Fig. 2A, lane 3). Strikingly, BHRF1-2 is also readily detected in the immunoprecipitates when the two wells were separately transfected with HA-Ago2 plasmid and BHRF1-2 mimic, but then mixed just before lysis and immunoprecipitation. This indicates that the association between Ago and BHRF1-2 is not representative of in vivo binding, having necessarily occurred after cell lysis (Fig. 2A, lanes 4). As expected, endogenous miR-16 is coimmunoprecipitated when HAAgo2 plasmid is transfected in conditions 2-4, and endogenous U6 snRNA, which does not bind Ago, does not coprecipitate. Together, these data demonstrate that the 


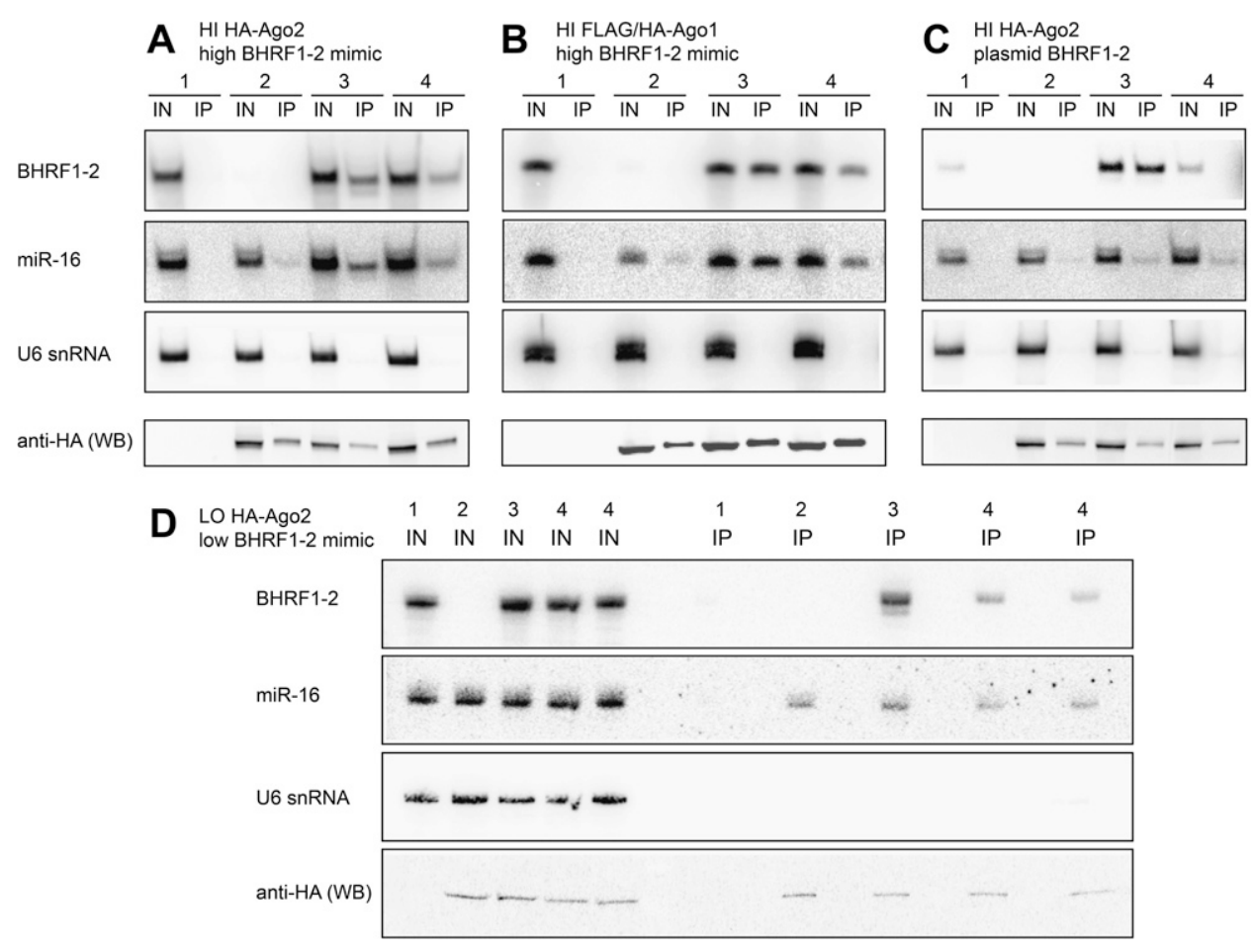

FIGURE 2. Coimmunoprecipitation experiments. Notations $1-4$ refer to the transfected cell mixtures that are depicted in Figure 1A. (A) High amounts of the HA-Ago2 plasmid ( $2 \mu \mathrm{g} /$ well) and of the BHRF1-2 mimic (100 pmol/well) were transfected. (B) As in Figure $2 \mathrm{~A}$, but substituting FLAG/HA-Ago 1 for HA-Ago2 plasmid. (C) High amounts of plasmids HA-Ago2 (2 $\mu \mathrm{g} /$ well) and pcDNA3-BHRF1-2 (2 $\mu \mathrm{g} /$ well) were transfected. $(D)$ Low amounts of both HA-Ago2 plasmid (100 ng/well) and BHRF1-2 mimic ( $5 \mathrm{pmol} /$ well) were transfected. In all cases, Northern blots were probed for BHRF1-2 miRNA (transfected), miR-16 miRNA (endogenous), and U6 snRNA (endogenous). Corresponding Western blots (WB panel) of cell lysate and immunoprecipitates were probed for HA-tagged Ago. In experiments $A-C$, IN stands for input cell lysate (10\% for RNA and protein); IP stands for immunoprecipitated material (90\% for RNA; $10 \%$ for protein). In experiment $D$, IN stands for input cell lysate (1.25\% for RNA and protein); IP stands for immunoprecipitated material (95\% for RNA; $5 \%$ for protein).

BHRF1-2 miRNA mimic can associate with Ago post-lysis when transfected in manufacturer-recommended quantities.

We asked whether in vitro association of miRNAs also occurs with other Ago proteins. Human Ago1-4 are generally viewed as being functionally redundant for miRNA-directed activities; all four proteins bind bulged miRNAs and mRNA partners in vivo ( $\mathrm{Su}$ et al. 2009). The results of our coimmunoprecipitation experiments were the same when we substituted FLAG/HA-Ago1 for HA-Ago2 (Fig. 2B).

We next asked how a plasmid-expressed miRNA behaves in the mixed lysate immunoprecipitation assays. As previously observed for other miRNAs (Winter and Diederichs 2011), BHRF1-2 accumulated to higher levels when cotransfected with HA-Ago2 (Fig. 2C, lane 3 IN). However, we were unable to detect any BHRF1-2 coimmunoprecipitating after cell lysate mixing, even though endogenous miR-16 was clearly coprecipitated with HA-Ago2 (Fig. 2C, lane 4 IP). Thus, plasmid-expressed BHRF1-2 does not associate with Ago post-lysis. However, the relative fraction of endogenous miR-16 that was coprecipitated was much lower than that of transfected BHRF1-2 (Fig. 2C, lane 3, cf. IP and IN), whereas this difference is not observed when synthetic miRNAs are transfected (Fig. 2A-D, lanes 3). The reason for this difference is unknown.
Synthetic miRNA mimics are easily transfectable and bypass the canonical miRNA biogenesis pathway, allowing them to accumulate intracellularly to extremely high levels relative to endogenous miRNAs (Fig. 1B). Due to limitations of plasmid transfection and possible oversaturation of limiting biogenesis components such as Drosha, Dicer, and export proteins, plasmid-expressed miRNAs do not typically accumulate to comparably high levels (Fig. 1B). To ask whether reducing the quantity of transfected miRNA mimic affects its ability to bind Ago post-lysis, we repeated the coimmunoprecipitation experiment using $1 / 20^{\text {th }}$ the amount of each miRNA mimic and HA-Ago2 plasmid (Fig. 2D). Despite the significantly reduced levels of both RNA and protein (Fig. 1B,C), the miRNA reproducibly associated with Ago post-lysis (Fig. 2D, lane 4 IP). Thus, the post-lysis association of BHRF1-2 mimic with Ago cannot be simply circumvented by lowering the abundance of both BHRF1-2 and HA-Ago.

\section{CONCLUSIONS}

We have demonstrated that antibodies directed against tagged human Ago1 and Ago2 can coprecipitate synthetic miRNA mimics that become available for binding only 
after cell lysis (Fig. 2A,B,D). In contrast, even maximal levels of plasmid-expressed miRNAs did not exhibit this behavior in the same experimental context (Fig. 2C). We were surprised by these results because the binding of a miRNA to Ago2 is high affinity (Lima et al. 2009; Tan et al. 2009), and each makes a considerable contribution to the stability of the other (Fig. 2C; Winter and Diederichs 2011; Elkayam et al. 2012).

Artificial introduction of miRNAs or Ago protein inevitably alters the stoichiometry of RISC components in the cellular environment. Because transfected miRNAs compete for a limited pool of protein-binding partners to form miRNPs, miRNA transfection results in both the downregulation of the mRNA targets of the transfected miRNA and global up-regulation of endogenous miRNA targets (Khan et al. 2009). Nonetheless, even transfection of low amounts of miRNA mimic and HA-Ago2 plasmid produced significant ex vivo association (Fig. 2D).

Because miRNA loading onto Ago precedes mRNA target loading (Czech and Hannon 2011), disruption of the Ago-miRNA association necessarily impacts the miRNA-mRNA interaction. Therefore, our findings have implications for both miRNA and mRNA target identification. We attempted to also explore the behavior of Ago-bound mRNAs upon mixing cell lysates. We found that, while known target mRNAs are enriched in immunoprecipitates from cells cotransfected with tagged Ago and full-length BHRF1 or firefly luciferase-LMP1 3' UTR mRNAs (Riley et al. 2012) (similar to Fig. 1A, scheme 3), the amount of coprecipitated mRNA in mixing experiments (similar to Fig. 1A, scheme 4) is highly variable from one experiment to the next (K Riley, T Yario, and J Steitz, unpubl.), thereby preventing firm conclusions. In contrast, high-throughput experiments that add a UV crosslinking step generate highly reproducible mRNA target data, including those using Ago and/or miRNA transfection (Chi et al. 2009; Hafner et al. 2010). In all cases, validation of miRNA targets by independent methods, such as luciferase assays with fulllength $3^{\prime}$ UTRs and Western blots of endogenous miRNA targets, is necessary. Thus, we have added another cautionary note to the growing list of concerns about miRNA target identification methods: artificial association with Ago postlysis, an artifact occurring upon transfection of synthetic miRNAs and tagged Ago.

\section{MATERIALS AND METHODS}

\section{Nucleic acids}

We cloned 566 bp of EBV genomic sequence encoding BHRF1-2 and BHRF1-3 between pcDNA3 EcoRI and XbaI sites using Raji cell genomic DNA as a template with $5^{\prime}$ PCR primer GACT GAATTCATCAGGGTCATTGGGCCTG and $3^{\prime}$ PCR primer GATCTCTAGAGGTTCTTCATCATTAACATAGCG to create plasmid pcDNA3-BHRF1-2. The empty control vector pcDNA3
(Invitrogen) was used as a control. N-terminally tagged HA-Ago2 in pCI-neo (Pillai et al. 2004) and FLAG/HA-Agol in pIRESneo (Meister et al. 2004) were kind gifts and were verified by sequencing. Synthetic BHRF1-2 mimic (IDT) was designed as previously described (Riley et al. 2012), using $20 \mu \mathrm{M}$ annealed guide (P-UAUCU UUUGCGGCAGAAAUUGA) and passenger (AAUUUCUGCCG CAAAAGACAGG) RNA strands.

\section{Cell culture and transfections}

HEK293T cells were grown in DMEM (Gibco) and Raji cells were grown in RPMI. Both media types were supplemented with $10 \%$ FBS, penicillin/streptomycin, and $2 \mathrm{mM} \mathrm{L}$-glutamine. The day preceding transfection, HEK293T cells were seeded in 6-well plates for $\sim 50 \%$ confluence at the time of transfection. Cells were transfected with $4 \mu \mathrm{g}$ of total plasmid (2 $\mu \mathrm{g}$ of each type of plasmid; $\mathrm{HI}$ ), $100 \mathrm{ng}$ of total plasmid (LO), 100 pmol of BHRF1-2 mimic (HI), and/or 5 pmol of BHRF1-2 mimic (LO) per well using $10 \mu \mathrm{L}$ per well Lipofectamine 2000 (Invitrogen) according to the manufacturer's instructions.

\section{Coimmunoprecipitations}

Pairs of wells of separately transfected cells were harvested together in the indicated combinations $24 \mathrm{~h}$ post-transfection and washed twice in phosphate-buffered saline. The cells were lysed in NET-2 buffer (100 mM Tris-HCl [pH 7.5], $150 \mathrm{mM} \mathrm{NaCl,} \mathrm{0.05 \%} \mathrm{NP-40}$ with $1 \times$ protease inhibitor cocktail [Roche]). The lysate was gently sonicated on ice $(3 \times 15 \mathrm{sec}$, low setting $)$ and centrifuged at $16,000 \mathrm{~g}$ and $4^{\circ} \mathrm{C}$ for $10 \mathrm{~min}$. For each immunoprecipitation, $30 \mu \mathrm{L}$ of protein G-Sepharose bead slurry (GE) was pre-washed in NET-2 and blocked at $4^{\circ} \mathrm{C}$ for $30 \mathrm{~min}$ in a solution containing $0.2 \mathrm{mg} / \mathrm{mL}$ of glycogen, $0.1 \mathrm{mg} / \mathrm{mL}$ of yeast tRNA, and $2 \mathrm{mg} / \mathrm{mL}$ of BSA. The cleared lysate was mixed with pre-blocked beads and $5 \mu \mathrm{L}$ of anti$\mathrm{HA}$ antibody (Covance). The mixtures were incubated $2-4 \mathrm{~h}$ at $4^{\circ} \mathrm{C}$, the beads were centrifuged at $200 \mathrm{~g}$ and $4^{\circ} \mathrm{C}$ for $2 \mathrm{~min}$, and the supernatant was collected for analysis. The beads were washed three times in NET-2 buffer, and the samples (input, supernatant, and immunoprecipitate) were split as noted and either subjected to TRIzol extraction to isolate coimmunoprecipitated RNAs or mixed with protein gel loading buffer for standard Western blotting. Results were replicated in at least three independent experiments with indistinguishable results.

\section{Northern blots}

RNA was isolated from indicated fractions of the input cell lysates or antibody-coated beads with TRIzol reagent (Invitrogen). Northern blots were carried out as previously published (Riley et al. 2010). The ebv-miR-BHRF1-2 and hsa-miR-16 miRNAs were probed with $5^{\prime}$ phosphate radiolabeled TCAATTTCTGCCG CAAAAGATA and CGCCAATATTTACGTGCTGCTA, respectively. U6 snRNA was probed as a loading control: GCAGGGGC CATGCTAATCTTCTCTGTATCG (Pfeffer et al. 2004).

\section{Western blots}

The indicated fractions of cell lysates were harvested in PBS, subjected to SDS-PAGE, and Western blots were performed as previously described (Riley et al. 2012). Primary antibodies were anti-HA (Covance), anti-GAPDH 14C10 (Cell Signaling Technology), 
anti-Ago2 (Millipore), and anti-pan-Ago 2A8 (Nelson et al. 2007), a gift from Z. Mourelatos. HRP-conjugated secondary antibodies (mouse, rabbit) were from Pierce. Western blots were visualized using the G:BOX (Syngene) chemiluminescence imaging system.

\section{ACKNOWLEDGMENTS}

We thank T. Tuschl (Rockefeller U.) for the HA/FLAG-Ago1 vector, W. Filopowicz (Friedrich Miescher Institute, Basel) for the HA-Ago2 vector, and Z. Mourelatos (U. of Pennsylvania) for the 2A8 anti-Ago antibody. Thanks to E. Guo and K. Tycowski for critical comments on the manuscript; A. Miccinello for editorial work; and all Steitz lab members for quality discussions. K.J.R. was supported by the American Cancer Society New England Division-Beatrice Cuneo Postdoctoral Fellowship. This work was supported in part by grant CA16038 from the NIH. J.A.S. is an investigator of the Howard Hughes Medical Institute. The content of this report is solely our responsibility and does not necessarily represent the official views of the NIH.

Received June 14, 2012; accepted June 18, 2012.

\section{REFERENCES}

Chi SW, Zang JB, Mele A, Darnell RB. 2009. Argonaute HITS-CLIP decodes microRNA-mRNA interaction maps. Nature 460: 479486.

Chi SW, Hannon GJ, Darnell RB. 2012. An alternative mode of microRNA target recognition. Nat Struct Mol Biol 19: 321-327.

Czech B, Hannon GJ. 2011. Small RNA sorting: Matchmaking for Argonautes. Nat Rev Genet 12: 19-31.

Didiano D, Hobert O. 2006. Perfect seed pairing is not a generally reliable predictor for miRNA-target interactions. Nat Struct Mol Biol 13: 849-851.

Dolken L, Malterer G, Erhard F, Kothe S, Friedel CC, Suffert G, Marcinowski L, Motsch N, Barth S, Beitzinger M, et al. 2010. Systematic analysis of viral and cellular microRNA targets in cells latently infected with human $\gamma$-herpesviruses by RISC immunoprecipitation assay. Cell Host Microbe 7: 324-334.

Easow G, Teleman AA, Cohen SM. 2007. Isolation of microRNA targets by miRNP immunopurification. RNA 13: 1198-1204.

Elkayam E, Kuhn CD, Tocilj A, Haase AD, Greene EM, Hannon GJ, Joshua-Tor L. 2012. The structure of human Argonaute-2 in complex with miR-20a. Cell 150: 100-110.

Ender C, Meister G. 2010. Argonaute proteins at a glance. J Cell Sci 123: $1819-1823$.

Grimson A, Farh KK, Johnston WK, Garrett-Engele P, Lim LP, Bartel DP. 2007. MicroRNA targeting specificity in mammals: Determinants beyond seed pairing. Mol Cell 27: 91-105.

Hafner M, Landthaler M, Burger L, Khorshid M, Hausser J, Berninger P, Rothballer A, Ascano M Jr, Jungkamp AC, Munschauer M, et al. 2010. Transcriptome-wide identification of RNA-binding protein and microRNA target sites by PAR-CLIP. Cell 141: 129-141.

Hendrickson DG, Hogan DJ, Herschlag D, Ferrell JE, Brown PO. 2008. Systematic identification of mRNAs recruited to Argonaute 2 by specific microRNAs and corresponding changes in transcript abundance. PLoS ONE 3: e2126. doi: 10.1371/journal.pone.0002126.

Hong X, Hammell M, Ambros V, Cohen SM. 2009. Immunopurification of Agol miRNPs selects for a distinct class of microRNA targets. Proc Natl Acad Sci 106: 15085-15090.

Karginov FV, Conaco C, Xuan Z, Schmidt BH, Parker JS, Mandel G, Hannon GJ. 2007. A biochemical approach to identifying microRNA targets. Proc Natl Acad Sci 104: 19291-19296.
Keene JD, Komisarow JM, Friedersdorf MB. 2006. RIP-Chip: The isolation and identification of mRNAs, microRNAs and protein components of ribonucleoprotein complexes from cell extracts. Nat Protoc 1: 302-307.

Khan AA, Betel D, Miller ML, Sander C, Leslie CS, Marks DS. 2009. Transfection of small RNAs globally perturbs gene regulation by endogenous microRNAs. Nat Biotechnol 27: 549-555.

Lewis BP, Burge CB, Bartel DP. 2005. Conserved seed pairing, often flanked by adenosines, indicates that thousands of human genes are microRNA targets. Cell 120: 15-20.

Lima WF, Wu H, Nichols JG, Sun H, Murray HM, Crooke ST. 2009. Binding and cleavage specificities of human Argonaute2. J Biol Chem 284: 26017-26028.

Meister G, Landthaler M, Patkaniowska A, Dorsett Y, Teng G, Tuschl T. 2004. Human Argonaute 2 mediates RNA cleavage targeted by miRNAs and siRNAs. Mol Cell 15: 185-197.

Mili S, Steitz JA. 2004. Evidence for reassociation of RNA-binding proteins after cell lysis: Implications for the interpretation of immunoprecipitation analyses. RNA 10: 1692-1694.

Nelson PT, De Planell-Saguer M, Lamprinaki S, Kiriakidou M, Zhang P, O’Doherty U, Mourelatos Z. 2007. A novel monoclonal antibody against human Argonaute proteins reveals unexpected characteristics of miRNAs in human blood cells. RNA 13: 17871792.

Orom UA, Lund AH. 2007. Isolation of microRNA targets using biotinylated synthetic microRNAs. Methods 43: 162-165.

Pasquinelli AE. 2012. MicroRNAs and their targets: Recognition, regulation and an emerging reciprocal relationship. Nat Rev Genet 13: $271-282$.

Pfeffer S, Zavolan M, Grasser FA, Chien M, Russo JJ, Ju J, John B, Enright AJ, Marks D, Sander C, et al. 2004. Identification of virusencoded microRNAs. Science 304: 734-736.

Pillai RS. 2005. MicroRNA function: Multiple mechanisms for a tiny RNA? RNA 11: 1753-1761.

Pillai RS, Artus CG, Filipowicz W. 2004. Tethering of human Ago proteins to mRNA mimics the miRNA-mediated repression of protein synthesis. RNA 10: 1518-1525.

Riley KJ, Rabinowitz GS, Steitz JA. 2010. Comprehensive analysis of Rhesus lymphocryptovirus microRNA expression. J Virol 84: 5148-5157.

Riley KJ, Rabinowitz GS, Yario TA, Luna JM, Darnell RB, Steitz JA. 2012. EBV and human microRNAs co-target oncogenic and apoptotic viral and human genes during latency. $E M B O J$ 31: 2207-2221.

Rio DC, Ares MJ, Hannon GJ, Nilsen TW. 2011. RNA: A Laboratory Manual. Cold Spring Harbor Press, Cold Spring Harbor, NY.

Shin C, Nam JW, Farh KK, Chiang HR, Shkumatava A, Bartel DP. 2010. Expanding the microRNA targeting code: Functional sites with centered pairing. Mol Cell 38: 789-802.

Su H, Trombly MI, Chen J, Wang X. 2009. Essential and overlapping functions for mammalian Argonautes in microRNA silencing. Genes Dev 23: 304-317.

Tan GS, Garchow BG, Liu X, Yeung J, Morris JP 4th, Cuellar TL, McManus MT, Kiriakidou M. 2009. Expanded RNA-binding activities of mammalian Argonaute 2. Nucleic Acids Res 37: $7533-7545$.

Ule J, Jensen K, Mele A, Darnell RB. 2005. CLIP: A method for identifying protein-RNA interaction sites in living cells. Methods 37: 376-386.

Wang Y, Juranek S, Li H, Sheng G, Tuschl T, Patel DJ. 2008. Structure of an argonaute silencing complex with a seed-containing guide DNA and target RNA duplex. Nature 456: 921-926.

Wang WX, Wilfred BR, Hu Y, Stromberg AJ, Nelson PT. 2010. AntiArgonaute RIP-Chip shows that miRNA transfections alter global patterns of mRNA recruitment to microribonucleoprotein complexes. RNA 16: 394-404.

Winter J, Diederichs S. 2011. Argonaute proteins regulate microRNA stability: Increased microRNA abundance by Argonaute proteins is due to microRNA stabilization. RNA Biol 8: 1149-1157. 

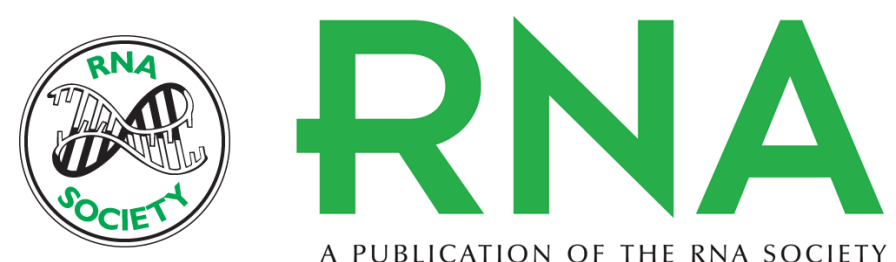

A PUBLICATION OF THE RNA SOCIETY

\section{Association of Argonaute proteins and microRNAs can occur after cell lysis}

Kasandra J. Riley, Therese A. Yario and Joan A. Steitz

RNA 2012 18: 1581-1585 originally published online July 26, 2012

Access the most recent version at doi:10.1261/rna.034934.112

$\begin{array}{ll}\text { References } & \begin{array}{l}\text { This article cites } 34 \text { articles, } 13 \text { of which can be accessed free at: } \\ \text { http://rnajournal.cshlp.org/content/18/9/1581.full.html\#ref-list-1 }\end{array}\end{array}$

Open Access Freely available online through the RNA Open Access option.

License Freely available online through the RNA Open Access option.

Email Alerting Receive free email alerts when new articles cite this article - sign up in the box at the Service top right corner of the article or click here. 